\title{
Enhancing Learning Opportunities in Higher Education: Best Practices that reflect on the Themes of the National Student Survey, UK
}

\section{Muhandiramge Kasun Samadhi Gomis}

School of Architecture and Built Environment, University of Wolverhampton, Wolverhampton, UK

\section{Mandeep Saini}

School of Architecture and Built Environment, University of Wolverhampton, Wolverhampton, UK

\section{Chaminda Pathirage}

School of Architecture and Built Environment, University of Wolverhampton, Wolverhampton, UK

\section{Mohammed Arif}

School of Architecture and Built Environment, University of Wolverhampton, Wolverhampton, UK 


\begin{abstract}
Purpose: This study assessed 'Learning Opportunities' provided to the undergraduate students, from level three to six, in Higher Education (HE). A knowledge gap was identified within the current practice relating to learning opportunities for Built Environment (BE) students in HE. The study focused on the themes under section two of the National Student Survey (NSS): how students explore ideas or concepts in-depth, bring information and ideas together from different topics, and apply the learned content in a real-life context. The study aimed to provide recommendations for enhancing 'Learning Opportunities' to the BE students within HE.
\end{abstract}

Methodology: Data collection focused on section two of NSS ‘Learning Opportunities’ and documentary analysis, and a qualitative survey was adopted for this study. A documental analysis of 334 Mid Module Reviews (MMR's) was carried out. The qualitative data was collected from level three to level six students and academics from Architecture, Construction Management, Civil Engineering and Quantity Surveying disciplines representing BE context. A sample of 40 students and 15 academics, including a Head of school, a Principal lecturer, Subject leads and lecturers, participated in interviews as part of a qualitative survey. Twelve drivers were developed using the data obtained through literature, documental analysis, and interviews. These drivers were analysed using manual content analysis to identify their influence on the specified themes under NSS section two and circulated among academics to be ranked by identifying its' influence to promote learning opportunities to BE students in HE.

Findings: This study highlighted twelve drivers which promote learning opportunities in HE within BE curriculum. Findings established that topics should be explained with more real-life or industry-orientated concepts such as simplification integrated into module delivery. Contrary to the literature, the use of physical materials (i.e. handouts and whiteboard) in addition to Virtual Learning Environment (VLE) for detailed explanations were considered effective in exploring concepts. During the current COVID-19 pandemic, context-based learning needs to be promoted by integrating videos of practical implementation for better understanding. The study recognised that lab, fieldwork and tutorials were essential to apply what students have learned in BE curricula to a real-life context.

Originality/Value: This study identified current learning approaches and provided recommendations to improve the $\mathrm{BE}$ students learning experience in $\mathrm{HE}$. The identified twelve drivers would significantly help academics and academic institutions to understand how learning opportunities should be facilitated in the BE curriculum to enhance student performances in HE.

Conclusion: Study identified twelve drivers that significantly contribute towards enhancing learning opportunities for BE students in the current HE context. It concludes that certain drivers should be prioritised in enhancing learning opportunities provided in $\mathrm{BE}$ curriculum. The study recommends that using traditional and VLE is essential to implement identified drivers and enhance the learning opportunities provided.

Keywords: National Student Survey, NSS Learning Opportunities, Teaching Practice in HE, Teaching and Learning Pedagogy, Quality in Education 


\subsection{Introduction}

Providing students with competent 'Learning Opportunities' is vital for HE academic development (Darling-Hammond et al., 2019). There is an evident use of obsolete learning opportunities which naturally exist in traditional pedagogy, which are still being used in current teaching practice (Wall, 2017 \& Aljawarneh, 2019). Some of the most popular opportunities in traditional learning are facilitating physical learning materials, group studies and discussions. Recent studies indicate that there need to be learning opportunities catered explicitly in developing the student experience, especially in BE sector (Fernández-Caramés and Fraga-Lamas, 2019; Diao and Shih, 2019). BE courses heavily rely on various students from different backgrounds and exposure levels, seeking an equal opportunity for learning and academic progression (Daniel et al., 2019). Thus, concepts of additional learning opportunities need to be identified, adopted and presented to the current context of learning in HE within the $\mathrm{BE}$ sector. BE knowledge providers consistently aim to improve their teaching practices in delivering holistic knowledge using innovative pedagogic strategies and tools. The National Student Survey (NSS) is a tool available within the UK HE in determining students' insight and feedback on their academic journey. Students assess the quality of the curriculum and their respective features of the academic programme through the eight sections given in the survey (Arthur, 2019). The insight given in each section influences potential improvements to be carried out in learning and teaching strategies implemented by HE providers. Thus, NSS further implies the aspects of academic enhancement in developing the overall student learning experience.

This study focuses on the second section of the NSS - Learning Opportunities, which are; Q4- exploring ideas or concepts in-depth, Q5- bring information and ideas together from different topics and Q6- applying the learnt content in a real-life context. The data obtained by NSS- section two in 2019 and 2020 highlights the need to enhance learning opportunities in the BE curricula. NSS records that the satisfaction level has reduced by $13 \%$ in the average minimum scoring criteria (Office for Students, 2020). It further identifies that the average percentile of section two of 2020 has decreased from $83 \%$ to $82 \%$ compared to 2019. NSS has recorded a significant decrease in Q5 and Q6, where it scored 30\% \& 30\% respectively in 2020 and $45 \%$ and $52 \%$ in 2019 . Additionally, the lack of learning opportunities presented to HE students due to the COVID-19 pandemic further accentuated its significance within BE curricula (Aristovnik et al., 2020). Therefore, it is ever more crucial to explore the knowledge gap in traditional and current 'Learning Opportunities' provided within HE identifying a best practice in BE curricula. These findings are further used to highlight the gap between the best practice and the current practice to provide 'Learning Opportunities' to BE students.

\subsection{Literature Review}

The literature identifies critical challenges such as lack of opportunities to provide an in-depth, industry-related and holistic understanding of subject matter within the BE curricula (Fernández-Caramés and Fraga-Lamas, 2019; Wall, 2017). Most of these challenges lie with traditional approaches in providing learning opportunities that need to be addressed in the current learning framework (Diao and Shih, 2019). The use of innovation and digitisation has changed from the traditional knowledge delivery methods and has promoted active learning strategies in curricula (Aljawarneh, 2019). However, a significant gap is identified in contemporary teaching practices to promote learning opportunities in the current HE context (Carrillo and Flores, 2020). Hence, the dire need for creating a best practice in learning opportunities need to focus on developing the learner experience within the current context of BE learning. 


\subsection{Providing opportunities to explore ideas or concepts in-depth.}

Knowledge and understanding are critical aspects of learning that determine academic and professional development (Ferdig, 2006). Thus, critical focus is needed in providing learning opportunities for offering knowledge and understanding within curricula. Currently, learners tend to interpret the concept of education from two perspectives (Johnson, 2013). The first reflects on mere knowledge acquisition in procreation from knowledge providers' discerning, known as knowledge reproduction. Knowledge reproduction is typically used for traditional assessment demands dominating the curriculum progress within the HE framework. Knowledge providers in academia insist that the learners accumulate knowledge from a broad conception and reflecting real-world scenarios (Ryan, 2013). In the academic learning experience, most of the practices are based on student-centred learning approaches (Goodyear and Dudley, 2015). Current learning approaches used in BE curricula provide an incentive to identify two educational functions: knowledge transferring (such as reflective, situational, problem solving and context-based education) and knowledge generation (further investigation on the learnt body of knowledge and implying the findings to develop personal understanding) to be student-centric (Mourato and Patrício, 2019). Facilitating both functions in education promotes a coherent and in-depth understanding of the learners' perspective. However, there is an eminent knowledge gap in the literature to disseminate how students can embed such flexibility in exploring ideas and concepts in-depth with the strict curriculum timeline within HE (Wade and Kidd, 2019).

Wade and Kidd (2019) discussed how concepts of pedagogical improvement tend to omit a critical element within knowledge transferring, i.e., how previous knowledge influencing the current knowledge generated, reflecting on real-world practice for active learning. As learners try to integrate the above functions of knowledge and implying it to a real-world context, a definitive and individualised understanding is created. According to Bloom et al. (1956), integrating knowledge into real-world context is considered the optimum learning and founding context-based learning concepts. However, identifying and analysing the connection between transferred and generated knowledge and applying it to real-world practices is challenging in curricula (Stockleben et al., 2016). Most of the BE assessment reflects the learners' ability to provide decisions on real-world scenarios, emphasising transferred and generated knowledge. Khan et al. (2018) identify that most learners find it challenging to contemplate within their academic experience. What literature fails to highlight is the concepts of 'decrypting' and understanding the knowledge transferred in utilising them to gain an in-depth understanding of HE. It is understood that a recipient could not grasp knowledge if the source of knowledge is not fully appreciated (Saini et al., 2019). Thus, it is essential to identify the factors promoting a better and in-depth understanding of knowledge transferring within curricula.

In promoting an in-depth understanding of knowledge transferring, the knowledge provider needs to implement a planned strategy in explaining the knowledge area (Saini et al., 2019). In the usual learning context, the knowledge area is defined, critical themes identified, the framework provided, links established and explained according to learner characteristics. Although most of these categories seem discretely proportional, the literature fails to identify a distinctive relationship with the concept of 'simplification', the strategy of active cognition as per the level of learner characteristics (Kalinowski et al., 2019). The simplification concept further reflects contemporary teaching methods, identifying the most effective and efficient way of transferring the knowledge to the learner, e.g. presenting real-life examples (Baytiyeh, 2017). Although it is evident that knowledge providers continuously reflect on real-life 
examples in knowledge transmission, literature is limited in identifying how it feeds-forward for knowledge generation. The best practice should suffice both knowledge transferring and generation with the implication within the industry where the student will have a holistic understanding of the body of knowledge discussed. However, the crucial aspects of all are not relating the content to the target audience. As previously discussed, most knowledge providers tend to overcomplicate knowledge without adapting to audience capacity. Thus, a strict code of practice needs to be developed to assist HE knowledge providers in enhancing knowledge transfer and better understanding within the BE curriculum to promote learning opportunities.

\subsection{Providing opportunities to bring information and ideas together from different topics}

Most knowledge providers tend to limit learners' academic experience, which could be assessed by the dimensions of knowledge and analysis (Kävrestad and Nohlberg, 2019; Khan et al., 2018). Most traditional approaches tend to transcend through singular dimensional and disciplinary boundaries lacking traditional knowledge delivery (Holley, 2017). The holistic approach in curricula provokes multi/complete dimensions in addressing knowledge transmission and helping other education functions. Studies (Ward, 2019 \& Uhlig, 2018) have confirmed that providing a holistic understanding will help learners improve their full potential in all dimensions thus, promoting learning opportunities within curricula. Many have identified key dimensions in need of addressing as intellectual, emotional, social, ethical, psychological, creative and intuitive, among many others (Mahmoudi et al., 2012). In addressing these dimensions, learners recognise a diversifying concept within the curricula that influence learners' critical thinking and reflect on the real world.

Reflective education practices offer clarity in interpreting and providing coherence in curricula and promote critical thinking. However, critical thinking would not be carried out at an optimum level when the learner dwells on knowledge achieved only from the classroom. Sugrue et al. (2017) argue, the 'complexity and diffusion' created by reflective academic practices leading to academic development results 'in lack of coherence'. Even if reflective education leads to context-based learning, which embraces innovation and focuses on knowledge in action, it does not provide different dimensions of forms of knowledge (Leitch and Day, 2000). For example, most of the module content and assessments in HE are based on context-based scenarios and recommend the learners provide 'their perspective' on the said scenario. The review establishes that the learner will not grasp a holistic understanding due to the nature of context-based/singular-dimensioned module content. Thus, promoting a multidimensional form of knowledge promoting holistic understanding is of utmost importance within academic development. Providing holistic knowledge further relates to Professional Standards and Regulatory Bodies (PSRB) in providing the minimum level of area and depth achieved within academic practices. PSRB acts as a strong foundation in providing holistic understanding and facilitating real-life knowledge in curricula. Studies carried out (UKPSF, 2013) aim to map the learning frameworks and other professional bodies, promoting multidimensional view on curricula from varied disciplinary perspectives.

In the current view of pedagogy, universal, social and environmental education needs further emphasis on developing holistic understanding (Miller, 2019). The BE curricula primarily reflect the universal pedagogical approach where the literature is inadequate with reflection on social and environmental approaches (Chandra et al., 2020). Also, the use of different dimensions of knowledge will be very challenging in knowledge provision due to the context of different disciplines operating within the BE sector. However, using diversified pedagogical approaches as above encourages learners to generate knowledge rather than to transfer it. Ceulemans and De-Prins (2010) presented a range of student-activating methods 
that can be applied to address holistic understanding. Among many, tutorial videos, brainstorming, reflecting with case studies, practical demonstrations, problem-based education, initiating discussion groups, oral presentations could be provided as examples. It is recommended that using the appropriate media (digital, tangible or a hybrid approach) in knowledge transfer is critical in developing learners' academic experience. Nonetheless, the literature fails to highlight guidelines in developing such teaching practice.

\subsection{Providing opportunities to apply what is learnt}

Context-based learning has addressed ecological validity within pedagogical learning approaches increasing student engagement and enhancing understanding (Pilot \& Bulte, 2006). Context-based learning is beneficial in locating the learners into a realistic setting where the student could implement procedural knowledge, further accentuating problem-solving skills, which are vital in providing learning opportunities. The study carried out by Kolb and Kolb (2011) reported an increased level of critical thinking where the students seem to connect more with theoretical knowledge with real-life application. The traditional learning approach was discouraged by focusing on short lecture periods in association with discussion, active feedback, and hands-on exposure. However, Kävrestad and Nohlberg (2019) have emphasised a limitation of critical thinking in traditional pedagogical aspects such as context-based learning due to a disciplinary approach in transferring knowledge. The multi-disciplinary effort made in real-life construction projects establishes a robust and holistic understanding among the learners; thus, concepts as work/site-based learning has been successful in current learning approaches (Brown and Tunnicliffe, 2017). Nonetheless, the literature is limited in highlighting the issues and limitations in taking the classroom into the real-life framework. Health and safety issues, strict curricula timelines, real-life learning not reflecting the curricula, diversity of intention been a few issues faced by both knowledge providers and learners (Kävrestad and Nohlberg, 2019). It was further stressed with the social distancing measures and the changes in teaching during the COVID-19 pandemic. Therefore, the optimum calibre of learning would be providing holistic understanding within the classroom limits. Consequently, the knowledge providers should instigate bringing the real-world context inside the classroom rather than taking the classroom outside.

A HE provider's main objective is to produce work-ready learners who have a holistic understanding upon completing their academic experience (Daniel et al., 2019). Thus, the pedagogical approach needs to focus on the application of knowledge effectively through holistic understanding. Application of knowledge dates back to the Experiential Learning Theory (ELT) model developed by Kolb (1984), which corresponds to four sub-stages of analysis in its reflective learning: Situation analysis, Problem analysis, Solution analysis, and Implementation analysis. Thus, providing stepping stones towards innovative pedagogical approaches as context-based learning and flipped room concept. Some of the application's attempts at integrating holistic understanding within the real-world practice into a classroom environment has not always been successful (Brown and Tunnicliffe, 2017; Walan et al., 2015). However, strategic pedagogical approaches such as flipped classroom and blended learning concepts have successfully integrated 'ecological validity in module delivery.

Moreover, digitisation has been recognised as one of the most effective learning approaches as it can provide systematic and creative blending experience across disciplines (Singh et al., 2019). However, studies (Blayone et al., 2017) found that digitisation struggle to co-exist, taking aside replacement alongside the dominant practices. Literature suggests a few of the most commonly used digitised practices are the VLE platforms and multimedia such as 
videos in knowledge transfer; using digitised technology as a tool implies efficient knowledge provision, support for knowledge generation, and illustrations of knowledge application effectively. Similarly, Masats and Dooly (2011) believe that using online platforms and promoting multimedia such as videos within the classroom environment offers learners and knowledge providers stimuli for personal, academic and professional development. However, even with the limitations of interpretation of digitised content and context, empirical studies revealed multimedia in apprehending inquiry-based learning, enhancing independent learning skills and supporting a cooperative learning environment (Singh et al., 2019). Nonetheless, the literature review establishes a lack of clear guidelines in literature signifies the need of linking the depth of knowledge within integrating digitised and other contemporary platforms in HE curricula.

\subsection{Methodology}

The three themes in section two of the NSS demanded investigating both the students' tacit knowledge and the teachers' applicability. The study was carried out on explicit knowledge through Mid Module Reviews (MMR) and tacit knowledge through interviews to perceive students' perspective of the learning opportunities provided. Three questions from NSS jointly capture the students' perspective and the level of learning opportunities provided in HE. In question one, the students reflect on the level of agreement with the provision of opportunities to explore ideas or concepts in depth. The second question determines the level of agreement with providing opportunities to bring information and ideas together from different topics in curricula. The final question determines the level of agreement with the provision of opportunities in applying what the student has learnt in a real-life context. A systematic research process led to fulfil the study's aim while exploring the current practices (both positive and negative) to identify what forms good practice and where improvements could be made in providing the learning opportunities to students. The reason for adopting different approaches to collect data is the nature of the explicit and tacit knowledge required (Saini, 2020).

Based on the NSS section two themes, a literature review was conducted to identify the strategies to provide learning opportunities. A total number of 334 MMR's from undergraduate (level three to six) students was analysed to establish the strategies offered to provide learning opportunities. Afterwards, the tacit knowledge contemplated within MMR's was analysed through interviews with 40 students and 15 academics, including the Head of school, a Principal lecturer, Subject leads and lecturers. For equal distribution and population size, ten students and three tutors were recruited randomly from each of the four disciplines (Architecture, Construction Management, Civil Engineering and Quantity Surveying), reflecting the diversity of the BE sector and while keeping a 95\% confidence level and 5\% margin of error.

The student sample size from each discipline and four levels of study (level three to six) gave a total sample size of eight full/part-time students and two apprenticeship students from each discipline. That formulates to ten students from each discipline and 40 from all four disciplines reflecting four levels of study. The three academic selection was based on the title and subject disciplines such as a Professor/Reader (subjected to availability), a Senior Lecturer and a Lecturer from each discipline. It gives a total sample size of 12 academics from four disciplines involved in teaching from level three to level six students. Further three participants, a Head of school, a Principal lecturer and a Subject lead was included to bring the sample size to 15. 
A wide range of data was obtained through interviews to understand the best practice in providing 'Learning Opportunities' a gainst the current practice established through literature review and MMR document analysis. The data obtained were accumulated into drivers and categorised according to the influence of each theme in NSS section two. These drivers were then recirculated among the academics, including the Head of school, a Principal lecturer, and Subject leads to be ranked according to the relative theme in NSS section two. The quality of the data captured and the number of responses gave the research team confidence in the data and indicated that valid inferences could be drawn from this data and a general conclusion to be established.

\subsection{Data Analysis}

The qualitative content analysis and document analysis are based on identifying the 'Learning Opportunities' for students to establish and recommend strategies to obtain the best practice. The data analysis presented some notable findings from this study.

\subsection{Providing opportunities to explore ideas or concepts in depth}

Taken altogether, the data presented here provide evidence in providing learning opportunities to the students in BE to explore ideas or concepts in depth. As per NSS data, 87\% of the participants agreed that their course had provided them with opportunities to explore ideas or concepts in-depth. This figure is a significant $5 \%$ improvement from the previous year's score, where the participants rated $82 \%$. One critical reason for the increase could be justified in a virtual learning environment (VLE), promoting students' current learning opportunities. However, data obtained from the MMR suggest that the students prefer simpler explanations. A similar theme was identified where the students stated: "Explanations of topics are sometimes difficult and complicated. We (Students) felt there could be a more [sic] simpler explanation". The study further suggests a need for appropriate media in knowledge transfer; "Use of handouts of each presentation and more whiteboard for detailed explanations". The academic staff agreed that both approaches, such as digitised and physical materials in teaching, are effective. However, mixed comments were identified where most full-time students preferred digitised materials, whereas part-time students preferred both approaches. The academic staff highlighted, "we (academic staff) tend to use more digitised approaches in teaching and promote paper-less learning indulging sustainability; however, it is best to provide handouts in the need of further clarification". However, this approach is minimal during the COVID-19 pandemic since most of the teaching is carried out majorly in VLE. Thus, students highlighted the lack of supportive learning documents and technology as a potential threat to learning in a pandemic situation. In summary, both academic and student participants accentuated blended learning as a pedagogic strategy using simpler explanations and providing tangible support with handouts or whiteboards were considered vital in providing opportunities to explore ideas or concepts in depth.

\subsection{Providing opportunities to bring information and ideas together from different topics}

This study's findings also establish that the lectures and topics should bring information and ideas together from different topics. Data obtained from the NSS states that $84 \%$ of the participants feel that the tutors have provided them with the opportunity to bring information and ideas together from different topics. Even though this percentile is in a higher quadrant, it is a $2 \%$ decline from the previous year's score, where the participants rated $86 \%$. The MMR 
seems to provide context as to why the students stated the reasons for decreased percentile. MMR data and student discussions highlight that there needs to be "More videos on practical implementation and work around the taught topic". Discussion from the academic staff led to believe that videos were used in their teaching strategy to bring real-world examples. However, the staff highlighted that "it is very challenging to find appropriate materials from third party media and integrate virtual/augmented application to curricula". Furthermore, they argued that the use of videos is limited to specific modules taught. Another interesting finding from student discussion is that a four-hour lecture does not add value to the learning but is exhausting. "Long-hour lectures in the morning are difficult, and we struggle to focus for long hour sessions", where the students demand more than one break for these sessions. The academics acknowledged the issue at hand but highlighted the limitations on addressing the issue. "We (academic staff) are mindful of the long-hour sessions but is limited by the strict timeline of the module delivery". The first half is designed for module delivery, and the other half to be designed for workshops to promote real-world context and provide opportunities for self-learning and bring information and ideas together from different topics. Nonetheless, both the students and academics confirmed that videos and efficient module delivery are critical in providing opportunities for bringing information and ideas together from different topics.

\subsection{Providing opportunities to apply what is learnt}

The study identifies the need for providing opportunities to apply what is learnt in a real-life context. As per NSS data, 77\% of participants agreed that the tutors provided the opportunities to apply what is learnt. Although this may look higher on the quadrant, it is a disappointment to earlier years' score, $84 \%$. Most replies highlighted the lack of alignment in theory and practice when it was raised in MMR's. A prominent factor identified by student discussion was that "Lectures and topics should be explained with more real-life examples". The discussion with academic staff emphasised that "these statistics provide insight into how crucial it is to identify the complications in context-based learning". Most of the academic staff highlighted the importance of work-based learning while accentuating the importance of workbased learning. Academic staff argues that the "privilege of real-life application is only available to the apprenticeship or the part-time students". However, the students claimed that "a real-life exposure is limited, considering the strict framework within the module content". In promoting real-life content in curricula, the academic staff stated that the common strategy was arranging site visits. Contrary to expectations, some students felt that "the site visits undertaken so far had not offered the opportunity to add value to the learning". Many students feel that site visits were more social events than anything else. Most of the academics agreed that "Site visits and virtual applications can be better planned... it is hard to manage site visits and augment virtual applications with limited time-frameworks of modules, management of large-cohorts, availability of consent, nature and relevance of real-world context". However, there was limited insight in using digitised media in creating opportunities to apply what is learnt. The data obtained from MMR has convincing evidence favouring incorporating practical elements (lab, fieldwork, tutorials) following on from theory in the modules as this allowed them to apply what they had learned.

Comparing the results obtained from the study, real-life context in teaching and using simpler explanations were identified as vital in enhancing learning opportunities. Furthermore, the emphasis was given on the impact of digitised learning where it was agreed that there is room for improvement in enforcing these digitised materials in enforcing practical implementation. A common theme was identified where handouts and whiteboards are preferred in apprehending fundamental knowledge and addressing detailed explanations. Nevertheless, data obtained from both MMR and interviews identifies that the core focus of 
providing learning opportunities is knowledge application. I.e. enabling the competency of the student in successfully applying what is learnt in a real-life context. The above data further determines how it would accommodate and drive towards enhancing the three themes in NSS section two. Thus, the discussion section provides further analysis in determining key drivers and the rationale behind how the drivers are ranked to enhance the three themes in NSS section two.

\subsection{Discussion}

As identified through the main findings in both the literature and data, there is a compelling need in providing Learning Opportunities in advancing the teaching practices within curricula. A significant correlation could be identified from the study's data with the literature reviewed. Evidence suggests that key emphasis should be considered in integrating reflective and context-based learning within the curricula in addition to integrating both traditional and digitised learning as a stimulus for best practice. The following discussion will share key findings and provide critical drivers that enhance learning opportunities for $\mathrm{HE}$ learners in BE.

\subsection{Best practice to provide opportunities to explore ideas or concepts in depth}

Providing a clear understanding of the concepts taught and allowing the learners to gain more knowledge has been a critical strategy in implementing pedagogy. A student-centred teaching approach has been a constructive indication within the current teaching framework (Goodyear and Dudley, 2015), where critical emphasis was given to knowledge transmission. Following drivers were identified as the best practice in providing opportunities to explore ideas or concept in depth.

- Using handouts, whiteboards, in addition to the lecture presentation, in presenting detailed explanations.

- The use of student-centred teaching approach in module delivery.

- Providing an in-depth understanding of the module content using knowledge 'simplification'.

- Using a variety of concepts as blended, reflective, situational, problem-solving and context-based education.

Although current knowledge transferring concepts are extensively used within academia, Stockleben et al. (2016) explain the challenges and the impact of orientating with the real-life scenario in providing in-depth understanding. With that in mind, Kalinowski et al. (2019) identify the use of simplification would be a strong base in developing an in-depth understanding reflecting the influence of industry orientation. The data analysis clarifies that most participants agree on the difficulty in understanding the knowledge transferred. A critical theme identified within student feedback was the difficulty in understanding subject content and the use of simpler explanations in module delivery. Both literature (Kalinowski et al., 2019) and primary data suggest that 'Simplification' and using a student-centred approach are critical in ensuring successful knowledge transmission and developing in-depth knowledge transfer within BE curricula. Since the above strategies pave the foundation for accommodating any other strategies, they will be deemed the most influential within the theme.

Furthermore, literature (Baytiyeh, 2017) and data analysis suggest that using both VLE platforms and physical supporting material to deliver lectures is deemed helpful. Additionally, 
using various teaching/learning concepts such as blended, reflective, situational, problemsolving and context-based education in compliance with other strategies should be a key concern in HE knowledge providers. At the current state, blended learning is proposed as the best pedagogic strategy with the use of simpler explanations with VLE focussed teaching and providing tangible support (i.e. handouts or whiteboards) is vital in enhancing opportunities to explore ideas or concepts in depth. Most participants opted for a hybrid technique of both digitised and traditional teaching methods within BE curricula development. Thus, digitised material would be further reinforced with a natural source in providing physical evidence within knowledge delivery. In dealing with more complicated module content, annotation (e.g. whiteboard/digital annotative media such as virtual reality and augmentation) could be used in providing a detailed explanation. However, physical learning materials are limited in current pedagogic practice due to the VLE teaching during the COVID-19 pandemic. Having these digitised materials developed into applications embedded through the cloud, VLE's needs to be researched and further developed. Even though these drivers were established in the HE context, the data analysis reflects essential guidelines, which must be adhered to in enhancing BE students' ability to explore ideas or concepts in depth in HE.

\subsection{Best practice to provide opportunities to bring information and ideas together from different topics}

According to the literature reviewed, providing holistic understanding following the reflective practices of teaching tends to be both successful and pragmatic. Sugrue et al. (2017) discuss the lack of coherence in current teaching practices, leading to a singular view of knowledge transfer. Following drivers were identified as the best practice in providing opportunities to bring information and ideas together from different topics.

- The usage of videos and other digitised media in a real-life context.

- Avoiding long-hour sessions in lectures provided.

- Use of tutorials, exams, coursework and work-based learning in applying holistic knowledge.

- Following a reflective practice orientating towards industry within teaching.

- Providing a holistic understanding of the module content by creating a multidimensional form of knowledge.

Both the literature and data recommend utilising a multi-dimensional/multidisciplinary form of knowledge and the reflection of industry practice in the BE, thus becoming the critical driver in bringing information together. The literature findings might concede within the parameters of student assessment criteria in developing holistic understanding. Contradictory to some literature, it was found that the tutorials, exams and coursework assessments need further accordance with BE work-based learning. However, the current pandemic has significantly depleted holistic knowledge where the students are restricted to a singular form of learning. The HE institutions and module tutors need to incline the module to be coherent and relevant to the industry practice, linking the gap between theory and practice within disciplines.

Previous studies found the importance of creating a multi-dimensional form of knowledge in improving the holistic nature of a subject (Miller, 2019; Holley, 2017 \& UKPSF, 2013). The study firmly confirms that the use of appropriate media helps in transferring knowledge to the learner. One repetitive emphasis from students was that there should be more videos and digitised media on practical implementation, accommodating industry orientation 
and creating a multi-dimensional/ multi-disciplinary form of knowledge transfer. The usage of more videos and similar media content on how practical implementation carried out in the industry was to be initiated in both face-to-face and VLE teaching environment. The final driver was obtained through an MMR documental analysis where the students insisted on attending long-hour lectures and the struggle in focussing through long-hour sessions echoing literature findings (Chika and Ombajo, 2017). The academic staff also agreed on the above and stated that the key focus must be on self-learning. It is identified that learning could be highly improved if the tutor was to give critical themes in knowledge and ask the students to explore further ideas and reflect these concepts in-depth with more real-life examples. The identified drivers will be fed forward in developing key drivers in enhancing opportunities to bring information and ideas together from different topics.

\subsection{Best practice to provide opportunities to apply what is learnt}

The key focus of this study is to identify and improve Learning Opportunities for the students. It was recognised that context-based learning carried out with ecological validity increases student engagement and enhancing understanding (Pilot \& Bulte, 2006). Following drivers were identified as the best practice in providing opportunities to apply what is learnt.

- Using digitised media and digitised platforms in enabling real-life context within the classroom.

- Promoting context-based learning with ecological validity in improving reallife knowledge application through VLE.

- Promoting module content reflecting site-based learning.

Additionally, studies carried out by Kolb and Kolb (2011) indicated that the impact of real-life knowledge application encouraging the use of context-based learning. Most of the student participants stated that more real-life content needs to be included within the lectures in applying what is learnt. However, due to the nature of the BE sector, only a limited number of students have the opportunity in applying the knowledge gained to a real-life context, i.e. apprenticeships, internships and part-time educational tenure. In addition to the lack of opportunity, the current pandemic has a substantial impact on students' academic development due to the lack of student-industry involvement. Most of the reasons include the timeframeworks of modules, management of large-cohorts, availability of consent, nature and relevance of real-world context. Widespread implications were using either a digitised platform to present real-life context within the classroom or providing industry-orientated module content for knowledge transfer. The use of guest speakers, discipline-specific videos, virtual reality and augmentation could be further integrated into the curricula. Use of site visits ranks as the least influential driver with an evident dissatisfaction from both the students and teachers in accommodating site visits into the curricula. However, despite the evidence produced in data analysis, it is clear that site visits could offer a more remarkable aptitude for consolidated learning. Thus, it would be necessary to plan and adjudicate the site visit context and provide what learning outcomes are being achieved through the site visits. As discussed, the above drivers will be fed forwards in developing critical drivers to enhance opportunities to apply what the student has learnt in a practical context.

The study has novelty and significant contribution in identifying the current need and approaches in enhancing learning opportunities to develop BE curricula in HE. Table 1 presents the critical drivers identified from both the primary and secondary data collection to enhance the learning opportunities in BE education. The drivers identified are presented according to their influence on each NSS theme and ranked by academics on how well they 
facilitate each theme in NSS section two. The study has demonstrated novelty and significant contribution by identifying critical issues in current BE learning and developing the best practice to enhance HE learning opportunities.

Table 1 - Drivers to enhancing Learning Opportunities in BE curricula in HE

\begin{tabular}{|c|c|c|}
\hline $\begin{array}{c}\text { Questions from } \\
\text { NSS }\end{array}$ & Drivers identified through the study & Rank \\
\hline \multicolumn{3}{|c|}{ Section Two: Learning Opportunities } \\
\hline \multirow{4}{*}{$\begin{array}{l}\text { 1. Providing } \\
\text { opportunities } \\
\text { to explore } \\
\text { ideas or } \\
\text { concepts in } \\
\text { depth. }\end{array}$} & $\begin{array}{l}\text { Providing an in-depth understanding of the module content } \\
\text { using knowledge 'simplification'. }\end{array}$ & D1 \\
\hline & $\begin{array}{l}\text { The use of student-centred teaching approach in module } \\
\text { delivery. }\end{array}$ & $\mathrm{D} 2$ \\
\hline & $\begin{array}{l}\text { Using a variety of concepts as blended, reflective, } \\
\text { situational, problem-solving and context-based education. }\end{array}$ & D3 \\
\hline & $\begin{array}{l}\text { Using handouts, whiteboards, in addition to the lecture } \\
\text { presentation, in presenting detailed explanations. }\end{array}$ & D4 \\
\hline \multirow{5}{*}{$\begin{array}{l}\text { 2. Providing } \\
\text { opportunities } \\
\text { to bring } \\
\text { information } \\
\text { and ideas } \\
\text { together from } \\
\text { different } \\
\text { topics. }\end{array}$} & $\begin{array}{l}\text { Providing a holistic understanding of the module content by } \\
\text { creating a multi-dimensional form of knowledge. }\end{array}$ & D1 \\
\hline & $\begin{array}{l}\text { Following a reflective practice orientating towards industry } \\
\text { within teaching. }\end{array}$ & D2 \\
\hline & $\begin{array}{l}\text { Use of tutorials, exams, coursework and work-based } \\
\text { learning in applying holistic knowledge. }\end{array}$ & D3 \\
\hline & $\begin{array}{l}\text { The usage of videos and other digitised media in a real-life } \\
\text { context. }\end{array}$ & D4 \\
\hline & Avoiding long-hour sessions in lectures provided. & D5 \\
\hline \multirow{3}{*}{$\begin{array}{l}\text { 3. Providing } \\
\text { opportunities } \\
\text { to apply what } \\
\text { the learner has } \\
\text { learnt in a } \\
\text { practical } \\
\text { context. }\end{array}$} & $\begin{array}{l}\text { Promoting context-based learning with ecological validity in } \\
\text { improving real-life knowledge application through VLE. }\end{array}$ & D1 \\
\hline & $\begin{array}{l}\text { Using digitised media and digitised platforms in enabling } \\
\text { real-life context within the classroom. }\end{array}$ & D2 \\
\hline & Promoting module content reflecting site-based learning. & D3 \\
\hline
\end{tabular}

\subsection{Conclusions \& Recommendations}

What stands out in this study is the general pattern of current practice in teaching and the significant room for improvement in providing 'Learning Opportunities' to the BE students. The study identified that modules with practical elements need to be well explained and resourced in providing a holistic module content as acceptable within the curriculum framework as a key driver in enhancing learning opportunities. Thus, concepts such as simplification and a student-centred approach in module delivery must be embraced in teaching. Consequently, detailed explanation in core contexts needs to be understandable and reflected with the real-world practices. Developing a curriculum representing the discipline in providing in-depth and holistic knowledge reflects the real-world context is critical; however, using various strategies as reflective, situational, problem-solving, and context-based education while adopting a student-centric teaching approach is demanded. The use of these 
practices develops essential functions in learning, known as conceptual knowledge and procedural knowledge.

It is recommended to provide a holistic understanding of the module content by creating a multi-dimensional form of knowledge to bring information and ideas together. This study confirms that digital media content as the base of learning platforms promoting practical implementation within the industry helps transfer holistic knowledge, especially within the current COVID pandemic. Moreover, this is further reflected by assessing students using tutorials, exams, coursework and work-based learning. Course leaders and module leaders must ensure that the programme's practical elements are well explained and resourced to bring information and ideas together.

Finally, it is established that the current digitised learning environment helps to enable the real-life context to apply what is learnt and promoted all the themes in NSS section two. It further confirms that using the digitised platform in presenting real-life context within real life has become essential. Discipline-specific videos, virtual reality and augmentation within module delivery need to be embraced during and after the COVID pandemic to develop learner engagement and provide learning opportunities within the BE curricula. This study further recommends using VLE as essential in enhancing teaching strategy to apply what is learnt in a practical context and providing overall 'Learning Opportunities' to the BE students in HE. However, even though the delivery be implied on a VLE basis, lecturers must ensure that explanations are technically detailed and understandable. Considering the diversity of students and the nature of $\mathrm{BE}$ knowledge, it is further recommended to integrate traditional/physical amenities (e.g. handouts and whiteboards) in presenting detailed explanations. Furthermore, the developed drivers recommend that priority be to develop a long-term strategy for 'Learning Opportunities' through practical elements that should have clearly explained outcomes to students. Therefore, the leaders must ensure appropriate support is available to provide 'Learning Opportunities' aligning the PSRB's and industry's requirements.

\section{Acknowledgement}

The data obtained for this study was based on a project guided by a steering committee within the University of Wolverhampton, chaired by Professor Mohammed Arif. Among the committee members, credit needs to be given to Stephen Wilkinson, Dr Amit Kaushik, Dr Lovelin Obi and Dr Nii Ankrah for their significant input on the data collection. Furthermore, both the student and academic participants at the University of Wolverhampton needs recognition for their insightful comments.

\subsection{References}

Aljawarneh, S., 2019. Reviewing and exploring innovative ubiquitous learning tools in higher education. Journal of Computing in Higher Education, 32(1), pp.57-73.

Aristovnik, A., Keržič, D., Ravšelj, D., Tomaževič, N. and Umek, L., 2020. Impacts of the COVID-19 Pandemic on Life of Higher Education Students: A Global Perspective. Sustainability, 12(20), p.8438.

Arthur, L., 2019. Evaluating student satisfaction - restricting lecturer professionalism: outcomes of using the UK national student survey questionnaire for internal student evaluation of teaching. Assessment \& Evaluation in HE, 45(3), pp.331-344. 
Baytiyeh, H., 2017, "The flipped classroom model: when technology enhances professional skills", International Journal of Information and Learning Technology, Vol. 34 No. 1, pp. 51-62.

Blayone, T., vanOostveen, R., Barber, W., DiGiuseppe, M. and Childs, E., 2017. Democratising digital learning: theorising the fully online learning community model. International Journal of Educational Technology in Higher Education, 14(1).

Bloom, B., Engelhart, M., Furst, E., Hill, W., \& Krathwohl, D. (Eds.) (1956). Taxonomy of Educational Objectives: The Classification of Educational Goals, Handbook I: Cognitive Domain. New York: David McKay.

Brown, N. and Tunnicliffe, M., 2017. Staff competencies/capabilities required and challenges faced when delivering project based learning courses. In: 28th Annual Conference of the Australasian Association for Engineering Education (AAEE 2017). Sydney, Australia: Australasian Association for Engineering Education, pp.696-705.

Carrillo, C. and Flores, M., 2020. COVID-19 and teacher education: a literature review of online teaching and learning practices. European Journal of Teacher Education, 43(4), pp.466-487.

Ceulemans, K., \& De Prins, M. 2010. Teacher's manual and method for SD integration in curricula. Journal of Cleaner Production, 18, 645-651.

Chandra, P., Tomitsch, M. and Large, M., 2020. Innovation education programs: a review of definitions, pedagogy, frameworks and evaluation measures. European Journal of Innovation Management, ahead-of-print(ahead-of-print).

Chika, E. and Ombajo, M., 2017. Lecture duration: A risk factor for quality teaching and learning in Higher Education. Integrity Journal of Education and Training, 1(1), pp.1-5.

Daniel, E., Oshodi, O., Gyoh, L. and Chinyio, E., 2019. Apprenticeship for craftspeople in the construction industry: a state-of-the-art review. Education + Training, 62(2), pp.159-183.

Darling-Hammond, L., Flook, L., Cook-Harvey, C., Barron, B. and Osher, D., 2019. Implications for educational practice of the science of learning and development. Applied Developmental Science, 24(2), pp.97-140.

Diao, P. and Shih, N., 2019. Trends and Research Issues of Augmented Reality Studies in Architectural and Civil Engineering Education-A Review of Academic Journal Publications. Applied Sciences, 9(9), p.1840.

Ferdig, R., 2006. Assessing technologies for teaching and learning: understanding the importance of technological pedagogical content knowledge. British Journal of Educational Technology, 37(5), pp.749-760.

Fernández-Caramés, T. and Fraga-Lamas, P., 2019. Towards Next Generation Teaching, Learning, and Context-A ware Applications for Higher Education: A Review on Blockchain, IoT, Fog and Edge Computing Enabled Smart Campuses and Universities. Applied Sciences, 9(21), p.4479.

Goodyear, V. and Dudley, D., 2015. "I'm a Facilitator of Learning!" Understanding What Teachers and Students Do Within Student-Centered Physical Education Models. Quest, 67(3), pp.274-289.

Holley, K., 2017. Interdisciplinary Curriculum and Learning in HE. Oxford Research Encyclopedia of Education.

Johnson, A. 2013. Educational psychology: Theories of learning and human development. El Cajon, CA: National Social Science Press. 
Kalinowski, E., Gronostaj, A. and Vock, M., 2019. Effective Professional Development for Teachers to Foster Students' Academic Language Proficiency Across the Curriculum: A Systematic Review. AERA Open, 5(1).

Kävrestad, J. and Nohlberg, M., 2019. Using context based micro training to develop OER for the benefit of all. Proceedings of the 15th International Symposium on Open Collaboration,.

Khan, S., Brunner, J. and Gibson, D., 2018. Changing the Mindset to Encourage Innovation in Resolving Problems in the Built Environment: Exploring the Role of Online Gaming Platforms to Deliver Collaborative Learning and Teaching. Journal of Regional and City Planning, 29(2), p.83.

Kolb, A. and Kolb, D., 2011. Experiential Learning Theory: A Dynamic, Holistic Approach to Management Learning, Education and Development. The SAGE Handbook of Management Learning, Education and Development, pp.42-68.

Kolb, D. A. 1984. Experiential learning: Experience as the source of learning and development (Vol. 1). Englewood Cliffs, NJ: Prentice-Hall.

Leitch, R. and Day, C., 2000. Action research and reflective practice: towards a holistic view. Educational Action Research, 8(1), pp.179-193.

Masats, D. and Dooly, M., 2011. Rethinking the use of video in teacher education: A holistic approach. Teaching and Teacher Education, 27(7), pp.1151-1162.

Miller, J., 2019. The Holistic Curriculum. 3rd ed. Toronto: University of Toronto Press.

Mourato, J. and Patrício, M.T. (2019), "Evaluation and control process in higher education institutions: a comparative analysis", Quality Assurance in Education, Vol. 27 No. 3, pp. 269-284. https://doi.org/10.1108/QAE-02-2019-0019

Office for Students, 2020. National Student Survey Results 2020. London, UK.

Pilot, A. and Bulte, A., 2006. Why Do You "Need to Know"? Context-based education. International Journal of Science Education, 28(9), pp.953-956.

Ryan, M., 2013. The pedagogical balancing act: teaching reflection in higher education. Teaching in Higher Education, 18(2), pp.144-155.

Saini, M., Arif, M., Kulanda, D. (2019), "Critical factors for transferring and sharing tacit knowledge within lean and agile construction processes", Construction Innovation, Vol. 18 Issue: 1, pp.6489

Saini, M., 2020 Simplified research methods: with exercises and examples. Wolverhampton: University of Wolverhampton.

Singh, J., Matthees, B. and Odetunde, A. (2021), "Leaning online education during COVID-19 pandemic - attitudes and perceptions of non-traditional adult learners", Quality Assurance in Education, Vol. ahead-of-print No. ahead-of-print.

Stockleben, B., Thayne, M., Jäminki, S., Haukijärvi, I., Mavengere, N., Demirbilek, M. and Ruohonen, M., 2016. Towards a framework for creative online collaboration: A research on challenges and context. Education and Information Technologies, 22(2), pp.575-597.

Sugrue, C., Englund, T., Solbrekke, T. and Fossland, T., 2017. Trends in the practices of academic developers: trajectories of HE?. Studies in HE, 43(12), pp.2336-2353. 
Uhlig, F., 2018. Holistic Teaching and Holistic Learning, Exemplified Through One Example from Linear Algebra. Challenges and Strategies in Teaching Linear Algebra, pp.353-367.

Wade, S. and Kidd, C., 2019. The role of prior knowledge and curiosity in learning. Psychonomic Bulletin \& Review, 26(4), pp.1377-1387.

Walan, S., Mc Ewen, B. and Gericke, N., 2015. Enhancing primary science: an exploration of teachers' own ideas of solutions to challenges in inquiry- and context-based teaching. Education 3-13, 44(1), pp.81-92.

Wall, T., 2017. A manifesto for higher education, skills and work-based learning. Higher Education, Skills and Work-Based Learning, 7(3), pp.304-314.

Wagener D., 2006. Promoting independent learning skills using video on digital language laboratories. Comp. Assist. Lang. Learn. 19(4-5):279-286.

Ward, S., 2019. A Student's Guide To Education Studies. 4th ed. Abingdon: Routledge. 